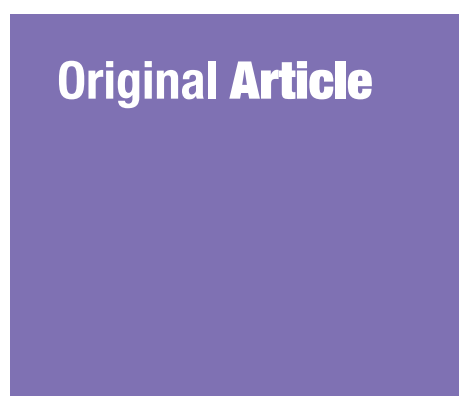

Submitted: 27 May 2016 Accepted: 3 May 2017 Online: 18 Aug 2017

\section{Awareness and Knowledge of Oral Cancer among Siamese Ethnic Group in Tumpat, Kelantan}

\author{
Nur Karyatee Kassim ${ }^{1,2}$, Munirah Mohd Adnan ${ }^{1}$, Chew Wei Wern', \\ LIM Zheng Ru ${ }^{1}$, Muhammad Hafiz HANAFI ${ }^{2}$, Azizah YusofF ${ }^{1}$ \\ School of Dental Sciences, Universiti Sains Malaysia, 16150 Kubang Kerian, \\ Kelantan, Malaysia \\ 2 School of Medical Sciences, Universiti Sains Malaysia, 16150 Kubang Kerian, \\ Kelantan, Malaysia
}

To cite this article: Kassim NK, Chew WW, Lim ZR, Hanafi MH, Yusoff A, Mohd Adnan M. Awareness and knowledge of oral cancer among Siamese ethnic group in Tumpat, Kelantan. Malays J Med Sci. 2017;24(4):47-54. https://doi. org/10.21315/mjms2017.24.4.6

To link to this article: https://doi.org/10.21315/mjms2017.24.4.6

\begin{abstract}
Introduction: Oral cancer is a life-threatening disease. Lack of public awareness is a potent barrier for the early detection of oral cancer, especially for high-risk populations.

Objective: This study aimed to determine the awareness and knowledge of the signs, symptoms and risk factors of oral cancer among a Siamese ethnic group in Tumpat, Kelantan. Methods: A cross-sectional study was conducted, using a guided questionnaire on sociodemography, habits, awareness and knowledge of the signs, symptoms and risk factors of oral cancer. Individuals under 18 years old and who had been diagnosed with oral cancer were excluded from this study.

Results: A total of 195 respondents participated, 61.5\% were female and the mean age was $46(1.64)$. About $41 \%$ of the respondents had received secondary education and $35.4 \%$ were illiterate. Most respondents were self-employed (21.5\%), followed by farmers (19.5\%) and housewives (20\%). The majority of them had a monthly income that fell below the poverty level of RM 830 (76.9\%). Among the respondents, $22.6 \%$ had the habit of smoking, $25.6 \%$ consumed alcohol, 8.2\% were betel quid chewers and $2.6 \%$ chewed tobacco. Out of 195 respondents, only $6.7 \%$ were aware of oral cancer. About 16.9\% of the respondents correctly answered all of the questions regarding the signs and symptoms of oral cancer and only $4.1 \%$ knew the risk factors of oral cancer. Conclusion: The awareness and knowledge of oral cancer in this targeted population were unsatisfactory. Future effective health promotion programs and education should be emphasised.
\end{abstract}

Keywords: oral cancer, Siamese, awareness and knowledge, signs and symptoms, risk factors

\section{Introduction}

Oral cancer, the 15th most common cancer globally, is one of the most life-threatening conditions worldwide $(1,2)$. The major risk factors for oral cancer have been established by numerous studies, including smoking, alcohol consumption and betel quid chewing (3). Besides these habitual factors, other factors such as human papilloma virus (HPV) infection, low intake of fruits and vegetables (4) and genetic susceptibility have been shown to influence the pathogenesis of oral cancer (5).

In spite of recent advances in the screening and management of oral cancer, the prognosis of oral cancer is still relatively poor. According to a study done in the United States, the 5-year survival rate for early-stage oral cancer is $83 \%$ (2). Almost $31 \%$ of cases were diagnosed at this stage. However, if the cancer has spread to surrounding tissues or organs and/or the regional lymph nodes, the 5 -year survival rate is 
$62 \%$. The 5-year survival rate is $38 \%$ if the cancer has spread to a distant part of the body (2). It had been reported that a majority of patients failed to recognise the early signs and symptoms of oral cancer (6). This may be due to a lack of awareness and information regarding the causes and knowledge of the signs and symptoms of oral cancer among the population. Most of the oral cancers are preventable if individuals know which risk factors can be controlled or eliminated. Early diagnosis of the malignancy is possible, greatly increasing survival rates.

There are only a few studies in Malaysia regarding oral cancer knowledge and awareness, especially among a high-risk, Siamese ethnic group in Kelantan. Kelantan was a former vassal state of Thailand, and it has been influenced by Thai customs and traditions in a way that makes this state's culture distinct from those of other states in Malaysia (7). Even though this ethnic group is small in number, their indulgence in risk habits such as tobacco use, quid chewing and alcohol drinking is considerable $(3,7)$. These habits may lead to the occurrence of oral mucosa lesions, which may be pre-malignant and eventually lead to significant morbidity and mortality.

This study on this Siamese ethnic group aimed to determine the awareness and knowledge of risk habits and warning signs of oral cancer within this Siamese community. It is hoped that these findings could help strengthen this population's awareness and knowledge, thus reducing the prevalence of high-risk habits associated with oral cancer.

\section{Materials and Methods}

A cross-sectional study was conducted among 195 Siamese ethnic respondents living in Tumpat, Kelantan. This study was conducted from February until September of 2015. The inclusion criteria for respondents of this study were that they were residents of Tumpat, Kelantan, that the respondents' fathers were Siamese (regardless of their mother's ethnic status) and that they were 18 years old and above (8). Those who had been diagnosed with oral cancer at any point in their lifetime were excluded from the study.

The sample size was calculated using the single proportion formula (9). In the calculation, the proportion was put as 0.336 , based on the percentage of correctly answered questions regarding alcohol as a risk factor of oral cancer
(10). The precision was set at 0.07 , giving a sample size of 175. Anticipating a 20\% nonresponse rate, a final sample size of 210 was decided upon. Simple, random sampling was done, based on the list given by the head of the villagers in order to determine the samples for the study.

A validated questionnaire, adapted from Agrawal et al. (10), was used to collect the data. It was translated from English into the Malay language. The questionnaire was used with the permission of the authors. The questionnaire consisted of 16 closed-ended questions designed to assess the respondents' awareness and knowledge of the signs, symptoms and risk factors of oral cancer. The questionnaire was divided into three parts: part A assessed the awareness of oral cancer, part B assessed the knowledge of signs and symptoms of oral cancer and part $\mathrm{C}$ assessed the respondents' knowledge of risk factors. This study differentiated between awareness and knowledge, based on the questionnaire by Agrawal et al. (10) and Formosa et al. (11). The response choices for each of the questions were categorised as 'incorrect', 'don't know' and 'correct'. One, most appropriate answer was required for each question. The answers were given the scores of 1, 2 and 3, respectively (10).

The questionnaire was also comprised of socio-demographic data such as age, gender, education level, literacy, occupation, monthly income and habits. In this study, literacy is defined as the ability of people 15 years old and above who can, with understanding, read and write a short, simple statement within their everyday life (12).

A pilot study was conducted among 20 Siamese individuals in Kampung Kubang Bemban, Tumpat, Kelantan to assess the comprehensibility of the questionnaire. This allowed for the evaluation of the clarity, suitability and length of the questions. Following this pilot study, the questionnaire was again revised after a conference call between the researchers.

Prior to the data collection, the respondents received explanations regarding the purpose of the study, and informed consent was obtained from the eligible respondents. The questionnaire was administered through face-to-face interviews to ensure that the respondents understood the questions without answers being prompted. After the interview sessions, the questionnaires were collected by the researchers and the data were entered in SPSS. 
Original Article | Awareness and knowledge of oral cancer

The data were analysed using IBM SPSS, Version 22.0. Basic, descriptive statistics were used to summarise the data. One-way ANOVA was used to compare the awareness, knowledge of signs, symptoms and risk factors across age and education levels, followed by a Bonferroni post hoc test to determine if a significant difference was found $(P<0.05)$; an independent $t$-test was used to compare between gender.

The study was approved by the Human Research and Ethics Committee, Universiti Sains Malaysia, on October 20, 2015 (USM/ JEPeM/150602018).

\section{Results}

A total of 214 eligible villagers were invited to participate in this study. However, only 195 responded, giving a response rate of $91 \%$. The non-respondents included both participants who refused to participate in this study and those who did not completely answer all of the questions given. The socio-demographic profile of the respondents is displayed in Table 1. The respondents' ages ranged from 18 to 85 years, with a mean of 46 (1.64). More than half of them were female (61.5\%). About $41 \%$ of the respondents had received secondary education and $35.4 \%$ were illiterate. Most respondents were self-employed (21.5\%), worked as farmers $(19.5 \%)$ or as housewives (20\%). The majority of respondents had monthly income that fell below the poverty level of RM 830 (76.9\%) (see Table 1). Among them, 22.6\% had the habit of smoking, 25.6\% consumed alcohol, $8.2 \%$ were betel quid chewers and $2.6 \%$ chewed tobacco (see Table 2).

Table 1. Distribution of respondents by socio-demographic profile $(n=195)$

\begin{tabular}{|c|c|c|c|}
\hline \multicolumn{2}{|c|}{ Socio-demographic profile } & \multirow{2}{*}{$\begin{array}{l}n \\
26\end{array}$} & \multirow{2}{*}{$\begin{array}{c}\% \\
13.3\end{array}$} \\
\hline Age (years) & $18-24$ & & \\
\hline & $25-34$ & 25 & 12.8 \\
\hline & $35-44$ & 40 & 20.5 \\
\hline & $45-54$ & 40 & 20.5 \\
\hline & $55^{-64}$ & 39 & 20.0 \\
\hline & $\geq 65$ & 25 & 12.8 \\
\hline Mean (SD) & $46(1.64)$ & & \\
\hline \multirow[t]{2}{*}{ Gender } & Male & 75 & 38.5 \\
\hline & Female & 120 & 61.5 \\
\hline \multirow[t]{4}{*}{ Education } & No formal education & 58 & 29.7 \\
\hline & Primary & 54 & 27.7 \\
\hline & Secondary & 80 & 41.0 \\
\hline & Tertiary & 3 & 1.5 \\
\hline \multirow[t]{2}{*}{ Literacy } & Literate & 126 & 64.6 \\
\hline & Illiterate & 69 & $35 \cdot 4$ \\
\hline \multirow[t]{7}{*}{ Occupation } & Student & 12 & 6.2 \\
\hline & Government servant & 5 & 2.6 \\
\hline & Business & 42 & 21.5 \\
\hline & Farmer & 38 & $19 \cdot 5$ \\
\hline & Housewife & 39 & 20.0 \\
\hline & Unemployed & 24 & 12.3 \\
\hline & Others & 35 & 17.9 \\
\hline \multirow[t]{3}{*}{ Monthly income } & $\leq \mathrm{RM} 830$ & 150 & 76.9 \\
\hline & RM831-RM180o & 33 & 16.9 \\
\hline & $\geq \mathrm{RM} 1801$ & 12 & 6.2 \\
\hline
\end{tabular}


Table 2. Distribution of respondents by habits (smoking, alcohol intake, chewing of betel quid and chewing of smokeless tobacco $)(n=195)$

\begin{tabular}{llcc}
\multicolumn{2}{c}{ Habits } & $\boldsymbol{n}$ & $\%$ \\
Smoking status & Non-smoker & 151 & 77.4 \\
& Ex-smoker & 12 & 6.2 \\
& Active smoker & 29 & 14.9 \\
& Social smoker & 3 & 1.5 \\
Alcohol intake & Yes & 50 & 25.6 \\
& No & 145 & 74.4 \\
Betel quid chewer & Yes & 16 & 8.2 \\
& No & 179 & 91.8 \\
Smokeless tobacco & Yes & 5 & 2.6 \\
chewer & No & 190 & 97.4 \\
\hline
\end{tabular}

The findings of this study revealed that more than half of the respondents (63.6\%) had heard about oral cancer. Only 13 respondents (6.7\%) answered all of the questions correctly. On top of that, $73.8 \%$ did not know that the risk of oral cancer increases with age, while $70.8 \%$ thought that treatment of oral cancer is impossible. About $67.7 \%$ of respondents had the misconception that oral cancer is contagious (see Table 3). The general awareness varied significantly throughout the different age groups $(P<0.001)$; for instance, awareness was significantly lower among respondents who were over 54 years old (see Table 4). Also, the awareness was higher in secondary and tertiary education groups $(P<0.001)$ (see Table 4$)$. No significant difference was observed in the general awareness between different genders $(P=0.112)$ (see Table 4).

Table 3 shows that only 33 respondents (16.9\%) correctly answered the questions regarding the signs and symptoms of oral cancer. Only $26.2 \%$ of the respondents knew that undue falling of teeth is a symptom for oral cancer. There were significant differences in the knowledge of signs and symptoms among the various age groups $(P=0.010)$. The knowledge was higher for the younger respondents, particularly in the age groups of 18 to 24 years old and 35 to 44 years old (see Table 4 ). However, the knowledge of signs and symptoms was not significant among different genders $(P=0.131)$.

This study also reported that only 8 respondents (4.1\%) fully understood the risk factors of oral cancer. Only 19\% of the respondents knew that family history of oral

Table 3. Mean (SD) and frequency (\%) of correct responses for individual questions.

\begin{tabular}{|c|c|c|c|}
\hline No. & Variables & $\%$ of correct responses & Mean (SD) \\
\hline & General awareness of oral cancer: & & \\
\hline 1. & Have you heard of oral cancer? & 63.6 & $2.3(0.96)$ \\
\hline 2. & Is prevention of oral cancer possible? & 36.4 & $2.3(0.61)$ \\
\hline 3. & Is treatment of oral cancer possible? & 29.2 & $2.2(0.65)$ \\
\hline 4. & Is oral cancer contagious? & 32.3 & $2.2(0.63)$ \\
\hline \multirow[t]{2}{*}{5.} & Does risk of oral cancer increase with age? & 26.2 & $2.1(0.64)$ \\
\hline & Knowledge of signs and symptoms of oral cancer: & & \\
\hline 6. & Growth of abnormal tissue & $35 \cdot 9$ & $2.3(0.63)$ \\
\hline 7. & Non-healing wound, intraoral, or on face/ around neck & 29.7 & $2.2(0.65)$ \\
\hline 8. & White or red spots & 33.8 & $2.2(0.66)$ \\
\hline 9. & Undue falling of teeth & 26.2 & $2.1(0.64)$ \\
\hline 10. & Reduced mouth opening & 30.8 & $2.2(0.65)$ \\
\hline \multirow[t]{2}{*}{11.} & Continuous pain in jaw & 26.2 & $2.2(0.66)$ \\
\hline & Knowledge of risk factors of oral cancer: & & \\
\hline 12. & Smoking & 45.6 & $2.3(0.69)$ \\
\hline 13. & Alcohol consumption & 31.3 & $2.1(0.71)$ \\
\hline 14. & Smokeless tobacco (e.g. betel nut) & 26.2 & $2.0(0.70)$ \\
\hline 15 . & Sedentary lifestyle & 27.2 & $2.1(0.70)$ \\
\hline 16. & Family history of cancer & 19.0 & $1.9(0.66)$ \\
\hline
\end{tabular}


Table 4. Association between socio-demographic characteristics and respondents' awareness and knowledge of oral cancer

\begin{tabular}{|c|c|c|c|c|}
\hline Variables & $n$ & $\begin{array}{l}\text { Awareness of oral } \\
\text { cancer } \\
\text { Mean (SD) }\end{array}$ & $\begin{array}{c}\text { Knowledge of risk } \\
\text { factors } \\
\text { Mean (SD) }\end{array}$ & $\begin{array}{l}\text { Knowledge of signs } \\
\text { and symptoms } \\
\text { Mean (SD) }\end{array}$ \\
\hline \multicolumn{5}{|l|}{ Age } \\
\hline $18-24$ & 26 & $11.3(2.18)$ & $11.2(1.92)$ & $14.3(3.22)$ \\
\hline $25-34$ & 25 & $11.6(1.96)$ & $10.2(2.29)$ & $12.7(3.55)$ \\
\hline $35-44$ & 40 & $11.6(2.21)$ & $11.1(2.44)$ & $14.1(3.04)$ \\
\hline $45-54$ & 40 & $11.6(2.07)$ & $10.1(2.40)$ & $13.0(3.61)$ \\
\hline $55^{-64}$ & 39 & $10.1(1.70)$ & $10.5(1.73)$ & $12.6(2.83)$ \\
\hline$\geq 65$ & 25 & $9.8(1.15)$ & $9.7(0.95)$ & $11.4(1.94)$ \\
\hline P-value & & $P<\mathbf{0 . 0 0 1}^{\mathrm{a}}$ & $P=0.032^{a}$ & $P=0.007^{a}$ \\
\hline \multicolumn{5}{|l|}{ Gender } \\
\hline Male & 75 & $10.7(1.89)$ & $9.95(1.99)$ & $12.5(3.02)$ \\
\hline Female & 120 & $11.2(2.13)$ & $10.8(2.13)$ & $13.5(3.26)$ \\
\hline P-value & & $P=\mathbf{0 . 1 1 2}^{b}$ & $P=0^{0.006}{ }^{b}$ & $P=\mathbf{0 . 0 3 5}^{\mathrm{b}}$ \\
\hline \multicolumn{5}{|l|}{ Education Level } \\
\hline No formal education & 58 & $9.7(1.40)$ & $9.9(1.53)$ & $12.1(2.29)$ \\
\hline Primary & 54 & $10.8(1.79)$ & $10.2(2.14)$ & $12.4(3.32)$ \\
\hline Secondary and Tertiary & 83 & $12.1(2.04)$ & $11.1(2.29)$ & $14.2(3.35)$ \\
\hline P-value & & $\boldsymbol{P}<\mathbf{0 . 0 0 1}^{\mathrm{a}}$ & $P=0.001^{a}$ & $P<0^{0.001} 1^{a}$ \\
\hline
\end{tabular}

Note: ${ }^{\mathrm{a}}=$ One-way ANOVA and $^{\mathrm{b}}=$ Independent $t$-test.

cancer is an important risk factor. Other than that, less than $30 \%$ of the respondents considered a sedentary lifestyle and the chewing of smokeless tobacco or betel quid as risk factors for oral cancer (see Table 3). The knowledge of risk factors was significantly different among the various age groups $(P=0.032)$.

\section{Discussion}

The Siamese ethnic group is a minority ethnic group of Kelantan. Even though this group is small in number, their indulgence in risk habits such as tobacco use, quid chewing and alcohol drinking is considerable. In fact, these habits may lead to the occurrence of oral cancer, which may be malignant, and, thus, to significant levels of morbidity and mortality $(3,7)$.

In this study, the general awareness of oral cancer was noted to be significantly higher within the younger age groups. It was also observed that the groups with higher education levels had better awareness of oral cancer, concurring with the study by Agrawal et al. (10). This may be due to the fact that the younger generations had greater media exposure and more chances to receive information regarding oral cancer. Bostock and Steptoe (13) stated that people who did not complete primary education had four times lower health literacy than those with degree-level qualifications. However, there were no remarkable differences observed in the awareness of oral cancer between genders.

About 22.6\% of the respondents knew that the undue falling of teeth is a symptom for oral cancer. The respondents' knowledge about other signs and symptoms of oral cancer, including abnormal tissue growth, non-healing wounds, white or red spots on the oral mucosa, a reduced mouth opening and continuous pain in the jaw, were also unsatisfactory. Findings from our study demonstrated that the respondents' general knowledge of signs and symptoms of oral cancer was particularly higher among the younger respondents and those with higher education levels. This implies that those who received higher education tend to have more exposure to this health knowledge and to be more involved in health campaigns. 
The knowledge of risk factors of oral cancer was considerably poor, with only $19 \%$ of the respondents reporting their awareness that a family history of oral cancer is an important risk factor. The general knowledge of risk factors for oral cancer throughout the age groups was statistically significant $(P=0.032)$. Gender and education levels also showed statistically significant results of $P=0.037$ and $P=0.002$, respectively. Younger respondents, females and those with higher educational qualifications had better knowledge regarding the risk factors of oral cancer. This result was similar to the previous study's finding by Agrawal et al. (10).

Based on the Malaysia Economic Planning Unit for 2012, the majority of our respondents (76.9\%) had a household income that fell below the poverty level, which was less than RM830.00; out of this subgroup, 29.7\% had no formal education. This is in accordance with Blanden and Gregg's study (14), which concluded that people with lower income or a lower socioeconomic status usually have a lower education level background. These factors indirectly lead to poorer levels of awareness and the input of health knowledge. From our study, females were observed to have better knowledge regarding the signs, symptoms and risk factors of oral cancer. This was also in agreement with the results of the study conducted by Agrawal et al. (10).

Our findings revealed that the prevalence of current smokers was $22.56 \%$, with more participating males (19.48\%) in comparison to females (3.08\%). This finding corresponded to the national prevalence of $21.5 \%$, according to the Malaysian Third National Health and Morbidity Survey (15). In our study, none of the smokers had awareness or knowledge of the risk factors of oral cancer. Furthermore, only one smoker knew about the signs and symptoms of malignancy. This demonstrated that the smokers in this study had low levels of awareness and knowledge pertaining to oral cancer. This has led to their continuation of unhealthy lifestyle habits that can give rise to oral cancer.

In our study, $8.2 \%$ of the respondents chewed betel quid, whereas $2.6 \%$ chewed smokeless tobacco. A previous study conducted by Sinor, Jessina, and Azizah (16) showed that the prevalence of quid chewing among Siamese in Kota Bharu was high (54.6\%). Another study by Guha et al. (17) reported that betel quid chewing, with or without added tobacco, increases individual's risk of oral cancer in an exposure-dependent manner, independent of tobacco and alcohol use. This same study also showed that the relative risk for oral squamous cell carcinoma was 7.74 for betel quid with tobacco, whereas the relative risk reduces to 2.56 for the use of betel quid without tobacco.

A prospective study by Maserejian et al. (18) showed that alcohol consumption is consistently related to a higher risk of oral cancer, regardless of the type of beverage consumed. In this study, $25.6 \%$ of the respondents consumed alcohol only, and the percentage of respondents who both drink alcohol and smoke was $15.4 \%$. This value was high in comparison with a previous study among the Siamese, which reported a percentage of alcohol consumption of 9\% (15). There is increasing evidence for a synergistic effect between drinking and smoking, raising individuals' risk of oral cancer far more than the effect of either drinking or smoking alone (19).

One of the limitations of this study was the data collection method, which was completely self-reported, especially regarding questions on risk-habits, household income and education level. There might be some recall bias since information on the frequency and duration of smoking, alcohol drinking and quid chewing may have been difficult for respondents to recall accurately. Also, the language barrier was a great struggle in carrying out the interview with some of the Siamese in Tumpat who could only converse in their mother tongue. This issue was overcome by asking those who are bilingual to translate and interpret the interviews, yet there may be a slight to significant deviation in the meaning through this translation and interpretation process.

In conclusion, our findings demonstrated that the awareness and knowledge of signs and risk factors for oral cancer among this Siamese ethnic group in Tumpat, Kelantan were generally low. Primary health care services should be carried out more frequently in Tumpat, Kelantan, and this Siamese ethnic population should be encouraged to participate in health education programs so that information regarding oral cancer and preventive methods can be conveyed effectively, allowing for early referral to specialists. The role of mass media in raising awareness, particularly television, newspaper and radio, should be emphasised as it was found to play a key role in encouraging health education and belief changes in this population. Brochures containing information on oral cancer, risk factors, details regarding the harm caused by tobacco use, alcohol and the early warning 
Original Article | Awareness and knowledge of oral cancer

signs and symptoms of oral cancer should be distributed as well. Furthermore, the initiation of intensive public education program for the recognition of early warning signs of oral cancer and early detection by mouth self-examination should be encouraged in Tumpat, Kelantan.

\section{Acknowledgements}

We would like to acknowledge Pusat Pengajian Sains Pergigian, Universiti Sains Malaysia for giving the necessary means and support for the completion of this study.

\section{Authors' Contributions}

Conception and design: NKK, AY

Analysis and interpretation of the data: MMA, CWW, LZR

Drafting of the article: CWW, LZR

Critical revision of the article for important intellectual content: NKK, AY, MHH

Final approval of the article: NKK, MHH

Provision of study materials or patients: MMA

Statistical expertise: MMA

Administrative, technical, or logistic support: AY, $\mathrm{MHH}$

Collection and assembly of data: CWW, LZR

\section{Correspondence}

Dr Nur Karyatee Kassim

Chemical Pathologist/Medical Lecturer

MBBS (UIAM), MMED (Chem. Path) (UM)

School of Dental Sciences, Universiti Sains Malaysia, 16150 Kubang Kerian,

Kelantan, Malaysia.

Tel: +6097676478

Fax: +6097675500

E-mail: karyatee@usm.my/drkaryatee@gmail.com

\section{References}

1. Torre LA, Bray F, Siegel RL, Ferlay J, LortetTieulent J, Jemal A. Global cancer statistics, 2012. CA: A Cancer Journal for Clinicians. 2015;65(2):87-108. https://doi.org/10.3322/ caac. 21262

2. Siegel RL, Miller KD, Jemal A. Cancer statistics, 2016. CA: A Cancer Journal for Clinicians. 2016;66(1):7-30. https://doi.org/10.3322/ caac. 21332
3. Yen TT, Lin WD, Wang CP, Wang CC, Liu SA. The association of smoking, alcoholic consumption, betel quid chewing and oral cavity cancer: A cohort study. European Archives of Otorhinolaryngology. 2008;265(11):1403-1407. https://doi.org/10.1007/s00405-008-0659-z

4. De Stefani E, Boffetta P, Ronco AL, Correa P, Oreggia F, Deneo-Pellegrini, et al. Dietary patterns and risk of cancer of the oral cavity and pharynx in Uruguay. Nutrition and Cancer. 2005;51(2):132-139. https://doi.org/10.1207/ S15327914nc5102_2

5. Drummond SN, Gomez RS, Noronha JCM, Pordeus IA, Barbosa AA, De Marco L. Association between GSTT-1 gene deletion and the susceptibility to oral squamous cell carcinoma in cigarette-smoking subjects. Oral Oncology. 2005;41(5):515-519. https://doi.org/10.1016/j. oraloncology.2004.12.014

6. West R, Alkhatib MN, McNeill A, Bedi R. Awareness of mouth cancer in Great Britain. British Dental Journal. 2006;200(3):167-169. https://doi.org/10.1038/sj.bdj.4813197

7. Sharis J, Azizah Y, Normastura AR, Rusdi AR. A study on oral mucosal lesions among adult Siamese ethnic group in Kelantan. Health and the Environment Journal. 2010;34.

8. Oral Health Division, Ministry of Health Malaysia. National oral health survey of adults (NOHSA) 20oo. Kuala Lumpur: Oral Health Division, Ministry of Health Malaysia; 2004.

9. Daniel, WW. Biostatistics: a foundation for analysis in the health sciences.8th ed. Hoboken, NJ: John Wiley \& Sons, Inc.; 2005.

10. Agrawal M, Pandey S, Jain S, Maitin S. Oral cancer awareness of the general public in Gorakhpur city, India. Asian Pac J Cancer Prev. 2012;13(10):5195-5199. https://doi.org/10.7314/ APJCP.2012.13.10.5195

11. Formosa J, Jenner R, Nguyen-Thi MD, Stephens C, Wilson C, Ariyawardana A. Awareness and knowledge of oral cancer and potentially malignant oral disorders among dental patients in far North Queensland, Australia. Asian Pac $J$ Cancer Prev. 2015;16:4429-4434. https://doi. org/10.7314/APJCP.2015.16.10.4429 
12. Street BV. Understanding and defining literacy: Scoping paper for EFA global monitoring report 2006; 2004. Unpublished manuscript.

13. Bostock S, Steptoe A. Association between low functional health literacy and mortality in older adults: longitudinal cohort study. The BMJ. 2012;344:e16o2. https://doi.org/10.1136/bmj. e1602

14. Blanden J, Gregg P. Family income and educational attainment: a review of approaches and evidence for Britain. Oxford Review of Economic Policy. 2004;20(2):245-263. https:// doi.org/10.1093/oxrep/grho14

15. Drummond SN, Gomez RS, Noronha JCM, Pordeus IA, Barbosa AA, De Marco L. Association between GSTT-1 gene deletion and the susceptibility to oral squamous cell carcinoma in cigarette-smoking subjects. Oral Oncology. 2005;41(5):515-519. https://doi.org/10.1016/j. oraloncology.2004.12.014

16. Sinor MZ, Jessina S, Azizah Y. Association between salivary parameters and oral mucosa lesions among Siamese population in Kelantan, Malaysia. Review of Progress. 2013;1(11):1-9.
17. Guha, N, Warnakulasuriya S, Vlaanderen J, Straif, K. Betel quid chewing and the risk of oral and oropharyngeal cancers: a meta-analysis with implications for cancer control. International Journal of Cancer. 2014;135(6):1433-1443. https://doi.org/10.1002/ijc.28643

18. Maserejian NN, Joshipura KJ, Rosner BA, Giovannucci E, Zavras AI. Prospective study of alcohol consumption and risk of oral premalignant lesions in men. Cancer Epidemiology and Prevention Biomarkers. 2006;15(4):774-781. https://doi.org/10.1158/ 1055-9965.EPI-05-0842

19. Petersen PE. Oral cancer prevention and control: The approach of the World Health Organization. Oral Oncology. 2009;45(4):454-460. https:// doi.org/10.1016/j.oraloncology.2008.05.023 